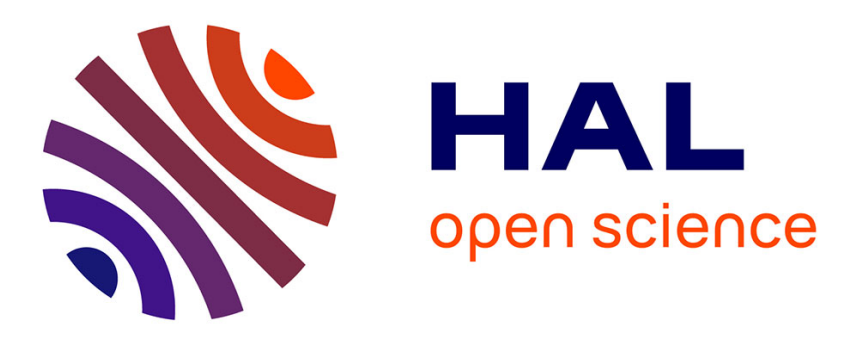

\title{
Molecular Upconversion in Water in Heteropolynuclear Supramolecular Tb/Yb Assemblies
}

\author{
Aline Nonat, Sylvana Bahamyirou, Alexandre Lecointre, Frederic Przybilla, \\ Yves Mely, Carlos Platas-Iglesias, Franck Camerel, Olivier Jeannin, Loïc J. \\ Charbonnière
}

\section{To cite this version:}

Aline Nonat, Sylvana Bahamyirou, Alexandre Lecointre, Frederic Przybilla, Yves Mely, et al.. Molecular Upconversion in Water in Heteropolynuclear Supramolecular Tb/Yb Assemblies. Journal of the American Chemical Society, 2019, 141 (4), pp.1568-1576. 10.1021/jacs.8b10932 . hal-02049516

\section{HAL Id: hal-02049516 https://hal-univ-rennes1.archives-ouvertes.fr/hal-02049516}

Submitted on 7 Mar 2019

HAL is a multi-disciplinary open access archive for the deposit and dissemination of scientific research documents, whether they are published or not. The documents may come from teaching and research institutions in France or abroad, or from public or private research centers.
L'archive ouverte pluridisciplinaire HAL, est destinée au dépôt et à la diffusion de documents scientifiques de niveau recherche, publiés ou non, émanant des établissements d'enseignement et de recherche français ou étrangers, des laboratoires publics ou privés. 


\section{INTRODUCTION}

The conversion of low energy photons into high energy ones, upconversion (UC), has been largely studied and applied for bulk solids ${ }^{1,2}$ and more recently for nanoparticles. ${ }^{3-5}$ However, the miniaturization of UC devices down to the molecular scale is still in its infancy, with only a handle of examples. ${ }^{6-10}$ Considering the issues associated with reproducibility, toxicity ${ }^{11}$ or particular side effects such as enhanced permeability and retention observed with nanoparticles in bioanalytical applications, ${ }^{12}$ the development of controlled discrete molecular probes represents an interesting alternative to alleviate these issues.

However, observing UC at the molecular scale in solution is a particularly challenging task ${ }^{13}$ as $\mathrm{OH}, \mathrm{NH}$ and $\mathrm{CH}$ oscillators encountered in the ligand backbones or in the solvent molecules are strong non-radiative competitors. ${ }^{14,15}$ They efficiently quench the intermediate excited states, especially in the Near-Infrared Region (NIR), before these later may be excited again to a higher emitting energy level. The main strategies developed to circumvent this drawback consist in: (i) protecting the cation with polydentate ligands fulfilling the first coordination sphere; (ii) deuteration ${ }^{16}$ or replacement of the ligand $\mathrm{C}-\mathrm{H}$ bonds by $\mathrm{C}-\mathrm{F}$ ones ${ }^{17}$ and (iii) displacing the solvent molecules as far as possible from the NIR emitters by introduction of bulky substituents on the ligand. ${ }^{8}$ The combination of these strategies has led to remarkable improvements of the luminescent properties of NIR complexes, especially in the case of $\mathrm{Yb} .{ }^{19}$ However, with a few exceptions, ${ }^{20}$ these successes concern organic solvents and there remain many efforts to be done to achieve similar results in water and aqueous solutions. Despite these drawbacks, molecular UC can afford advantages over the solid state approach. Typical synthetic procedures for the preparation of bulk solids or nanoparticles require grinding, high temperatures or annealing procedures, which result in a random distribution of active centres in the matrices. However, it was noticed by Auzel and Goldner ${ }^{21}$ that some synthetic procedures could lead to a "clustering effect" with chemical clusters of few $\AA$ in size, in which the ion-ion interactions are tremendously increased. Thus, a directed molecular or supramolecular approach allows for a better control of the distances and ordering of the active centres and their gathering at the $\AA$ range, which might improve UC and 
partly counterbalance the drawbacks of quenching oscillators.

It has long been demonstrated that Energy Transfer Upconversion (ETU) is among the most efficient mechanism to observe the UC phenomenon, even in the cases of molecular systems. ${ }^{22}$ The combination of one or more intermediate donor atoms (sensitizers) relaying energy to the emitting acceptor centre affords potential advantages in terms of efficiency. With its single ${ }^{2} \mathrm{~F}_{7 / 2} \rightarrow$ ${ }^{2} \mathrm{~F}_{5 / 2}$ electronic transition at ca $980 \mathrm{~nm}$, trivalent $\mathrm{Yb}$ is the element of choice to act as a sensitizer. This transition is high enough in energy to prevent full quenching of the excited state by water $\mathrm{OH}$ oscillators. Furthermore, the energy difference between the two ${ }^{2} \mathrm{~F}$ Yb energy level matches those of different electronic transitions of numerous other trivalent lanthanides such as Er, Ho, Tm, $\mathrm{Tb}$ or Eu.

A particularly interesting case is that of the $\mathrm{Yb} / \mathrm{Tb}$ sensitizer/acceptor pair. Although there is no electronic transition of $\mathrm{Tb}$ corresponding to the ${ }^{2} \mathrm{~F}_{5 / 2}$ energy level of $\mathrm{Yb}$, it has been observed that $\mathrm{Yb}$ can photosensitize $\mathrm{Tb}$ in solids through a mechanism of cooperative sensitization (Figure 1).23 The simultaneous deactivation of two $\mathrm{Yb}$ centres is accompanied by energy transfer to the Tb atom which then emits in the visible region.

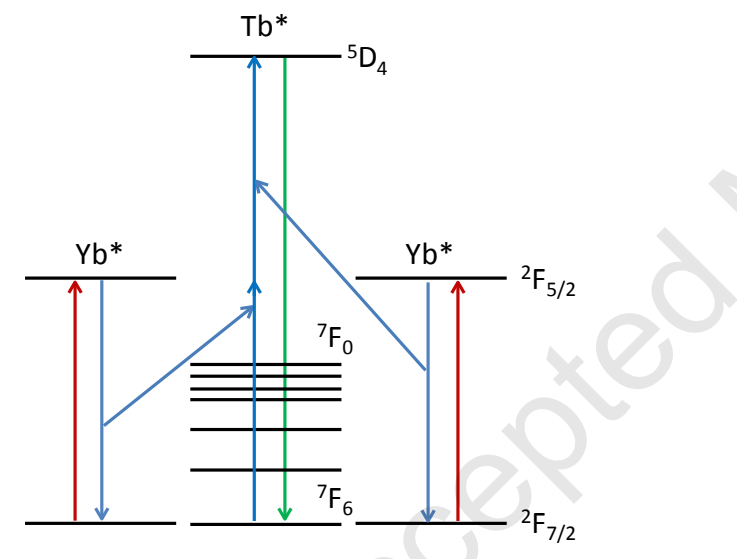

Figure 1. Principle of cooperative UC photosensitization of Tb by $\mathrm{Yb}^{23}$

Alternatively, the UC mechanism leading to $\mathrm{Tb}$ emission upon $\mathrm{Yb}$ excitation was attributed in some instances to a mechanism involving ground state absorption (GSA) followed by excited state absorption (ESA). However, this mechanism holds for $\mathrm{Yb} / \mathrm{Tb}$ pairs having very short intermetallic distances (3.89 $\AA$ for $\mathrm{Cs}_{3} \mathrm{~Tb}_{2} \mathrm{Br}_{9}$ doped with Yb). ${ }^{24}$ Furthermore, it could only be observed at low temperatures, for which the phonon assistance to cooperative sensitization is no longer efficient. ${ }^{25}$ The distinction between the two main mechanisms GSA/ESA or cooperative sensitization UC is generally made by pulsed excitation experiments, showing immediate increase of UC emission for ESA, but a slow rise of the UC emission intensity after pulsed excitation, due to the supplementary energy transfer step, for cooperative sensitization. ${ }^{23}$

Within the framework of our research on lanthanide coordination chemistry, we have recently developed a series of phosphonated ligands. Ligands containing phosphonate functions generally impart a larger thermodynamic stability to Ln complexes than their carboxylate counterparts. ${ }^{26,27}$ Bulkier than carboxylates, phosphonates engender steric compression around the metal ion, which often results in a decrease of the coordination number $(\mathrm{CN})$. This may lead to the removal of water molecules from the first coordination sphere of lanthanides as for the octadentate ligand $1,4,7,10-$ Tetraazacyclododecane-1,4,7,10-tetraacetic acid ligand (DOTA, $\mathrm{CN}=9)^{28}$ compared to $1,4,7,10-$ tetraazacyclododecane-1,4,7,10-

tetrakis(methylenephosphonic acid) ligand (DOTP, $\mathrm{CN}=$ $8),{ }^{29}$ or for the heptadentate pyridine tetracarboxylate ( $\mathrm{CN}$ $=9)^{30}$ compared to its phosphonated analogue $(\mathrm{CN}=8) .^{31}$ Finally, the negative charges of the phosphonate functions bring significant second sphere contributions to the relaxivity of $\mathrm{Gd}$ complexes, ${ }^{32}$ which can become as important as the contribution of the first sphere.33 Interestingly, the second sphere interactions of mononuclear phosphonated lanthanide complexes can be favourably mastered to construct higher order polynuclear 34,35 and heteropolynuclear ${ }^{10}$ species.

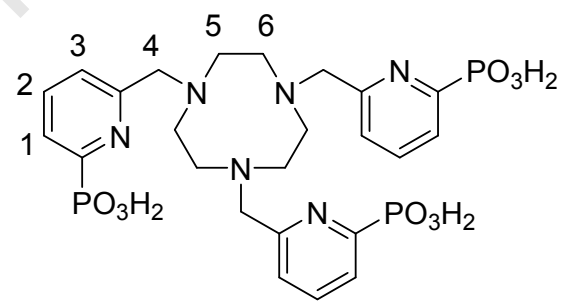

Scheme 1. Ligand $L$ and the $H$ atom numbering for NMR spectral assignment

Taking advantage of this principle, we here demonstrate that the mononuclear complex of $\mathrm{L}$ (Scheme 1) with $\mathrm{Yb}$, noted (YbL) can form supramolecular species of formula $\left[(\mathrm{YbL})_{2} \mathrm{~Tb}_{\mathrm{x}}\right](\mathrm{x}=1$ or 2$)$ in the presence of $\mathrm{Tb}$ cations in aqueous solutions. In these adducts, NIR excitation of $\mathrm{Yb}$ at $980 \mathrm{~nm}$ resulted in a cooperative photosensitization of $\mathrm{Tb}$ with emission in the visible region. The assembly process was studied by a combination of various spectroscopic techniques and the resulting UC phenomenon was quantitatively and mechanistically investigated in $\mathrm{D}_{2} \mathrm{O}$. Taking advantage of the optimized conditions determined from $\mathrm{D}_{2} \mathrm{O}$, the UC conversion process evidenced in non-deuterated water for the first time from a molecular specie.

\section{RESULTS AND DISCUSSION}

Solid state and solution structure of the (YbL) complex. The (YbL) complex was prepared according to literature procedure. 34 Slow evaporation of an aqueous 
solution of the (YbL) complex resulted in the formation of crystals suitable for X-ray crystal structure analysis (Figure 2).

The structure is composed of an $\mathrm{Yb}(\mathrm{III})$ cation embedded into the cavity formed by the 1,4,7-Triazacyclononane (tacn) ligand with the three pyridyl arms being wrapped around the cation. The $\mathrm{Yb}$ atom is nine coordinated with three nitrogen atoms from the tacn macrocycle, the three pyridyl nitrogen atoms and three oxygen atoms from the phosphonic acid moieties. The three strands are wrapped around the metal providing a pseudo- $C_{3}$ axis passing through the $\mathrm{Yb}$ atom and perpendicular to the plane formed by the nitrogen atoms of the tacn cycle. The wrapping led to the formation of $\Delta$ and $\Lambda$ isomers. Both isomers are present in the centrosymmetric crystal structure. Using the SHAPE program,,$^{36}$ the geometry of the first coordination sphere of $\mathrm{Yb}$ was shown to be very close to a spherical trigonal prism, which is characterized by identical center-to-vertex distances. ${ }^{37} \mathrm{The} \mathrm{Yb}$ atom is almost contained in the plane formed by the three nitrogen atoms of the pyridyl rings with a slight deviation from the mean plane of $0.003 \AA$. The three phosphonate functions are monoprotonated, allowing a compensation of the overall charge and the formation of a neutral complex. a

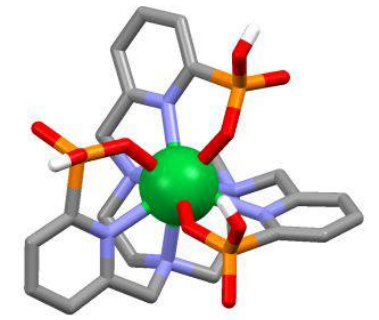

b

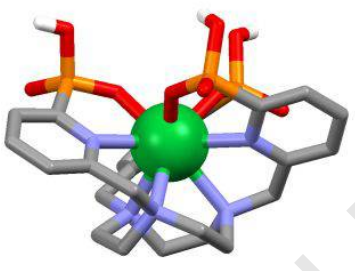

Figure 2. X-Ray crystal structure of the (YbL) complex viewed along (a) and perpendicularly (b) to the pseudo- $C_{3}$ axis.

The structure of the $\mathrm{Yb}$ complex in solution was further studied by analyzing the ${ }^{1} \mathrm{H}$ paramagnetic lanthanide induced shifts (LIS)..$^{8}$ The ${ }^{1} \mathrm{H}$ NMR spectrum presents the 9 paramagnetically-shifted signals expected for an effective $C_{3}$ symmetry in $\mathrm{D}_{2} \mathrm{O}$, observed in the range 24 to $-18 \mathrm{ppm}$ (Figure $\mathrm{S} 1$ and Table S1, Supp. Inf.). The attribution of the proton signals was achieved by linewidth analysis, as the broadening of the ${ }^{1} \mathrm{H}$ signals induced by the paramagnetism of the metal ion is proportional to $1 / r^{6}$, where $r$ is the distance between the observed nucleus and the paramagnetic ion. ${ }^{39}$ Thus, the ${ }^{1} \mathrm{H}$ NMR signals of axial protons $(\mathrm{r}(\mathrm{Yb} \cdots \mathrm{H})=3.4-4.2 \AA)$ are considerably broader than those of the equatorial resonances $(\mathrm{r}(\mathrm{Yb} \cdots \mathrm{H})=4.4-4.5$ $\AA$ ). The paramagnetic shifts induced by $\mathrm{Yb}^{3+}$ are dominated by the pseudo-contact (PC) mechanism, which in the case of axially symmetric systems can be expressed as: $3^{8}$

$$
\delta^{P C}=D_{1} \frac{\left(3 \cos ^{2} \theta-1\right)}{r^{3}}
$$

In (1), $r$ is the distance between the paramagnetic ion and the observed nucleus, while $\theta$ is the angle defined by the $\mathrm{Yb}-\mathrm{H}$ vector and the principal magnetic axis of the system and $\mathrm{D}_{1}$ is a proportionality constant related to the axial component of the magnetic susceptibility tensor.

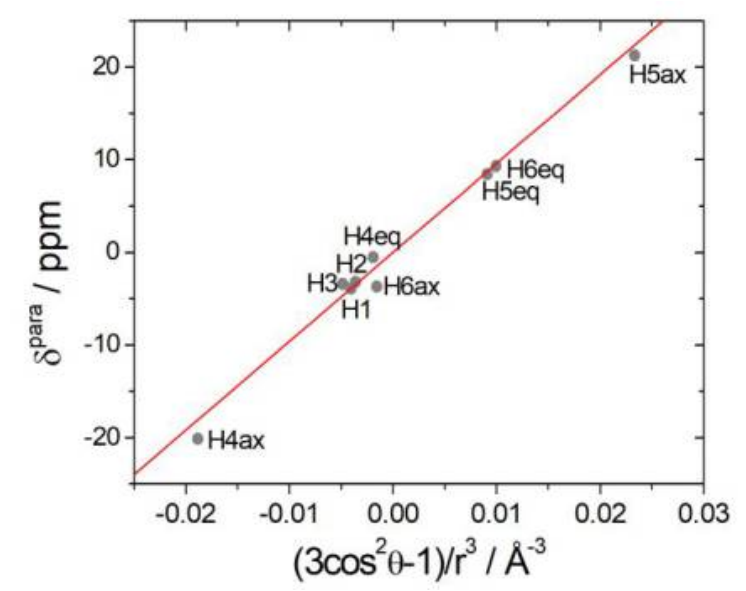

Figure 3. Plot of the paramagnetic shifts versus the geometric factors for the different proton nuclei of the $\mathrm{Yb}^{3+}$ complex. The red line corresponds to the linear fit of the data (See Scheme 1 for $\mathrm{H}$ atom labeling).

The paramagnetic shifts ( $\left.\delta^{\text {para }}\right)$ observed for the $\mathrm{Yb}^{3^{+}}$ complex were analyzed with Eq (1) using the chemical shifts observed for the $\mathrm{Lu}^{3+}$ diamagnetic analogue to estimate the diamagnetic contribution $\left(\delta^{\text {dia }}\right)$ to the observed chemical shifts ( $\left.\delta^{\text {bbs }}\right)$ :

$$
\delta^{\text {para }} \approx \delta^{p C}=\delta^{\text {bss }}-\delta^{\text {dia }}
$$

The geometric terms $\left(3 \cos ^{2} \theta-1\right) / \mathrm{r}^{3}$ of the different nuclei of the $\mathrm{Yb}^{3^{+}}$complex were estimated from both the X-ray structure and density functional theory (DFT) calculations (Table $\mathrm{S}_{1}$ and $\mathrm{S}_{2}$ )..$^{\circ}$ The structure obtained by DFT is very similar to the X-ray structure described above.

Plots of the observed paramagnetic shifts versus the geometric factors provide straight lines passing through the origin. The linear correlation obtained from this analysis is better when using the DFT geometry $\left(R^{2}>\right.$ o.994) than the X-ray structure $\left(R^{2}>0.988\right)$, indicating that DFT provides a better description of the structure of the complex in solution. Nevertheless, the $\mathrm{Yb}^{3+}$ complex retains the axially symmetric $C_{3}$ structure observed in the solid state upon dissolution in water. The slope of the linear plot provides $D_{1}=960 \mathrm{ppm} \AA$ (Figure 3 ). The value of $D_{1}$ obtained for this complex is ca. 3 times smaller than those reported for cyclen-based complexes showing capped square antiprismatic coordination, ${ }^{41,42}$ and about $56 \%$ of the value reported for the tris(dipicolinate) $\mathrm{Yb}^{3+}$ complex $\left(D_{1} \sim 1700 \mathrm{ppm} \AA^{3}\right)$. ${ }^{3}$ This points to a rather small anisotropy of the ${ }^{2} \mathrm{~F}_{7 / 2}$ ground state in the $\mathrm{Yb}^{3+}$ complex investigated here. ${ }^{44}$

The electronic absorption spectrum of the (YbL) complex in $\mathrm{D}_{2} \mathrm{O}$ (Figure $\mathrm{S}_{2}$ ) in the NIR region displays a broad absorption band centred around $980 \mathrm{~nm}$ which corresponds to the ${ }^{2} \mathrm{~F}_{7 / 2} \rightarrow{ }^{2} \mathrm{~F}_{5 / 2} \mathrm{Yb}$ transition. The radiative lifetime of $\mathrm{Yb}$ in the complex in $\mathrm{D}_{2} \mathrm{O}, \tau_{\text {rad }}$, was calculated from this spectrum using the methodology developed by Werts and coworkers ${ }^{45}$ (see Supplementary information 
for full details). A radiative lifetime of $1.36 \mathrm{~ms}$ was determined, which provides a metal centred luminescence efficiency of $0.75 \%$ using equation (3):

$$
\phi_{Y b}=\frac{\tau_{o b s}}{\tau_{r a d}}
$$

Where $\tau_{o b s}$ is the measured luminescence lifetime of the complex in $\mathrm{D}_{2} \mathrm{O}(10.2 \mu \mathrm{s} 35)$. It is to be noticed that a long $\mathrm{Yb}$ excited state lifetime is of critical importance for the observation of UC in the system. As two excited $\mathrm{Yb}$ atoms have to transfer their energy to $\mathrm{Tb}$, the probability of such a transfer is strongly depending on the probability to have excited pairs, hence on the excited state lifetime of the $\mathrm{Yb}$ centers.

Cooperative UC sensitization in $\mathrm{D}_{\mathbf{2}} \mathrm{O}$. We have recently shown ${ }^{35}$ that the addition of excess $\mathrm{Ln}^{3+}$ cations to solutions of the $[\mathrm{LnL}]$ complexes led to the formation of two new species with $\left[(\mathrm{LnL})_{2} \mathrm{Ln}\right]$ and $\left[(\mathrm{LnL})_{2} \mathrm{Ln}_{2}\right]$ compositions. These polynuclear complexes were found to be inert, so that exchange of one Ln chelated inside the cavity of the ligand by a second Ln' cation added into the solution does not occur at neutral $\mathrm{pH}$. From this observation, we hypothesized that addition of up to one equivalent of $\mathrm{Tb}$ cations to a solution of the [YbL] complex would lead to the formation of the heteropolynuclear $\left[(\mathrm{YbL})_{2} \mathrm{~Tb}\right]$ and $\left[(\mathrm{YbL})_{2} \mathrm{~Tb}_{2}\right]$ complexes, with potentially interesting properties in terms of cooperative UC photosensitization, according to:

$$
2(\mathrm{YbL}) \stackrel{\mathrm{Tb}^{3+}}{\longrightarrow}\left[(\mathrm{YbL})_{2} \mathrm{~Tb}\right] \stackrel{\mathrm{Tb}^{3+}}{\longrightarrow}\left[(\mathrm{YbL})_{2} \mathrm{~Tb}_{2}\right]
$$

To further confirm the absence of scrambling into the solution, ${ }^{1} \mathrm{H}$ - and ${ }^{3} \mathrm{P}-\mathrm{NMR}$ experiments were run using a solution of $[\mathrm{YbL}]$ in $\mathrm{D}_{2} \mathrm{O}(\mathrm{pD}=7.7)$, to which 0 , 0.5 and 1.0 equivalents of $\mathrm{LuCl}_{3}$ were added. A second experiment consisted in the addition of one equivalent of $\mathrm{YbCl}_{3}$ to a solution of $[\mathrm{LuL}](\mathrm{pD}=7.9)$. The spectra measured immediately after addition of the salt or after 7 days at $80^{\circ} \mathrm{C}$ are identical. However the two experiments provided very different spectra (Figure S9), showing smaller paramagnetic shifts when the paramagnetic $\mathrm{Yb}$ atom was added to the [LuL] complex. These results confirmed the lack of scrambling in these conditions. Additionally, ${ }^{1} \mathrm{H}-$ NMR spectra of solutions of 0.5 and 1.0 equivalent of $\mathrm{TbCl}_{3}$ to a $\mathrm{D}_{2} \mathrm{O}$ solution of the [YbL] complex were even less informative with the concomitant effects of the paramagnetic contributions of $\mathrm{Tb}$ and $\mathrm{Yb}$ (Figure Sio and Si1). Finally, a potential scrambling of the two kinds of lanthanide inside/outside the ligands was checked by luminescence spectroscopy experiments in which 0.5 and 1.o equivalent of $\mathrm{EuCl}_{3}$ were added to solutions of [YbL] in water. Excitation into the ligand absorption band $(267 \mathrm{~nm})$ revealed an Eu centred emission, as a result of the spatial proximity of $\mathrm{Eu}$ and the ligands in the polynuclear assemblies. However, determination of the luminescence lifetimes were particularly informative (Figure S12). The decay of the solution at 0.5 eq., associated to the formation of the $\left[(\mathrm{YbL})_{2} \mathrm{Eu}\right]$ as the main species with our model, was satisfactorily fitted with a mono-exponential decay with a lifetime of $655 \mu \mathrm{s}$. The decay of the equimolar solution, associated to the formation of $\left[(\mathrm{YbL})_{2} \mathrm{Eu}_{2}\right]$ as the main species, was fitted with a bi-exponential decay with lifetimes of $257 \mu \mathrm{s}(44 \%)$ and $659 \mu \mathrm{s}(56 \%)$. All the lifetimes determined are far below the value expected for an Eu cation embedded into the cavity of the ligand $(1.26 \mathrm{~ms}), 35 \mathrm{a}$ good evidence of the lack of scrambling, at least on the timescale of the experiments at room temperature and also after four days of heating at $70^{\circ} \mathrm{C}$ after which no significant changes could be observed.

To confirm our hypothesis, a solution of $(\mathrm{YbL})$ in $\mathrm{D}_{2} \mathrm{O}$ was titrated by increasing amounts of a solution of $\mathrm{TbCl}_{3} \cdot 6 \mathrm{H}_{2} \mathrm{O}$ in $\mathrm{D}_{2} \mathrm{O}$. After each addition of aliquots of Tb salts, the $\mathrm{pD}$ of the solution was raised to 7.0 and the emission spectrum of the solution was recorded in the visible region upon 980 $\mathrm{nm}$ excitation. A $850 \mathrm{~nm}$ high-pass filter was placed between the excitation source and the sample to remove possible second order artefacts. Figure 4 represents the typical emission spectrum observed upon addition of 1.0 equivalent of $\mathrm{TbCl}_{3} \cdot 6 \mathrm{H}_{2} \mathrm{O}$, while the inset shows the evolution of the emitted signal as a function of the number of equivalents of $\mathrm{Tb}$ added to the (YbL) solution.

From Figure 4 , it clearly appears that the emission spectrum results from the ${ }^{5} \mathrm{D}_{4} \rightarrow{ }^{7} \mathrm{~F}_{\mathrm{J}}(\mathrm{J}=6$ to 3 ) transitions of $\mathrm{Tb} .{ }^{6}{ }^{6}$ The decrease of the intensity above one equivalent was ascribed to the formation of a precipitate, as previously observed in the case of the NMR titration of $\mathrm{L}$ by $\mathrm{Lu}$ at $\mathrm{mM}$ concentrations. 35 In order to evidence the importance of the $\mathrm{Yb}$ complex in the UC process, and to exclude a possible sensitization of $\mathrm{Tb}$ by a non-linear excitation of the ligand, a similar titration was performed using the optically silent $[\mathrm{LuL}]$ complex in place of [YbL]. Excitation at $980 \mathrm{~nm}$ resulted in the total absence of $\mathrm{Tb}$ emission during the titration. To further characterize the UC sensitization of $\mathrm{Tb}$, the intensity of the $\mathrm{Tb}$ emission was recorded as a function of the excitation power density.

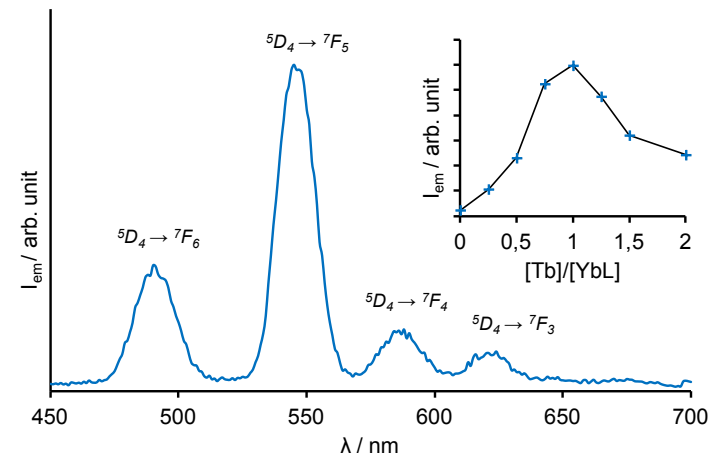

Figure 4. Emission spectrum measured upon addition of 1.0 equivalent of $\mathrm{TbCl}_{3} \cdot 6 \mathrm{H}_{2} \mathrm{O}$ to a $1.25 \mathrm{mM}$ solution of $(\mathrm{YbL})$ in $\mathrm{D}_{2} \mathrm{O}$ at pD $7.1\left(\lambda_{\mathrm{exc}}=980 \mathrm{~nm}, P_{980}=1.08 \mathrm{~W}\right)$. Inset: Evolution of the emission intensity as a function of the $[\mathrm{Tb}] /[\mathrm{YbL}]$ ratio.

The corresponding Log-Log plot shown in Figure 5 clearly evidences a slope of almost 2, representative of the 
quadratic dependence of a two photon excitation mechanism. 47

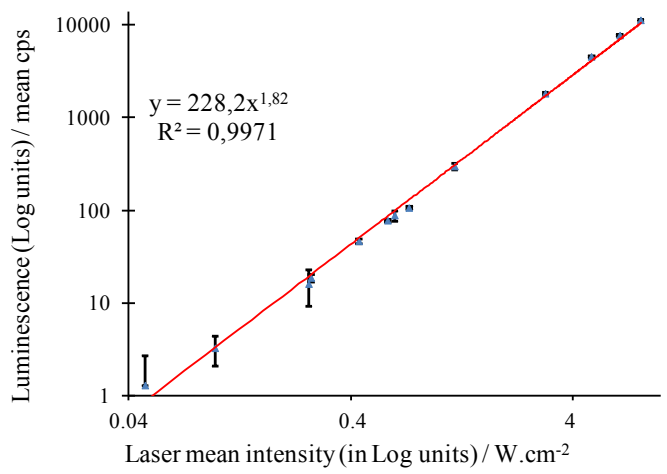

Figure 5. Log-Log plot of the Tb emitted intensity at $545 \mathrm{~nm}$ as a function of the excitation intensity of the $975 \mathrm{~nm}$ laser for a $1.53 \mathrm{mM}$ solution of $(\mathrm{YbL})$ in $\mathrm{D}_{2} \mathrm{O}$ containing 0.5 equivalent of $\mathrm{TbCl}_{3} \cdot 6 \mathrm{H}_{2} \mathrm{O}$ at $\mathrm{pD}=9.2$.

Interestingly, the $\mathrm{pD}$ of the solution appeared to be a very important factor and an order of magnitude in the emission intensity could be gained by adjusting the $\mathrm{pD}$ of the solution. Importantly, the adjustment must be done only after the addition of the $\mathrm{Tb}$ salts, to avoid the formation of insoluble $\mathrm{Tb}$ hydroxy species. The best $\mathrm{pD}$ range was found to be close to 9.15 (Figure $\mathrm{S}_{3}$ ).

Determination of the UC luminescence quantum yield in $\mathrm{D}_{\mathbf{2}} \mathbf{O}$. Full experimental details for the calculation of the UC quantum yield, $\mathrm{QY}_{\mathrm{UC}}$, can be found in the Supplementary Information section. It consisted in using the basic definition of the luminescence quantum yield as being the ratio of the number of emitted photons to the number of absorbed photons, while comparing the emitted signal (Figure $\mathrm{S}_{4}$ ) to that of a $\mathrm{Tb}$ reference (Figure $\mathrm{S}_{5}$ )..$^{8}$ By applying this methodology, $\mathrm{QY}_{\mathrm{UC}}$ was determined to be $1.4 \times 10^{-8}$ with a large relative uncertainty of $\pm 20 \%$. Accordingly, this $\mathrm{QY}_{\mathrm{UC}}$ value should better be considered as an order of magnitude rather than an absolute figure.

Mechanistic study of the UC process in $\mathrm{D}_{2} \mathrm{O}$. Literature data on $\mathrm{Tb} / \mathrm{Yb}$ codoped systems describe different mechanisms for the observed UC emission of Tb. A first possible mechanism consists in the successive excitation of two $\mathrm{Yb}$ atoms, followed by their simultaneous energy transfer to populate the $\mathrm{Tb}$ excited state, as represented in Figure ${ }^{23}$ This mechanism is related to the GSA/ETU mechanism observed in conventional UC probes. A fingerprint of this mechanism is a slow rise of the UC emission before decay after a pulsed excitation.

A second mechanism refers to $\mathrm{Yb}$ - $\mathrm{Tb}$ exchange coupled dimers, ${ }^{24}$ in which the Ln atoms are close enough in space to allow some exchange interactions. This mechanism is then described by:

$$
\left|Y b\left({ }^{2} F_{7 / 2}\right), T b\left({ }^{7} F_{6}\right)\right\rangle+h v \rightarrow\left|Y b\left({ }^{2} F_{5 / 2}\right), T b\left({ }^{7} F_{6}\right)\right\rangle+h v \rightarrow\left|Y b\left({ }^{2} F_{5 / 2}\right), T b\left({ }^{5} D_{4}\right)\right\rangle
$$

For this mechanism, relevant to the principle of GSA/ESA mechanism of conventional UC processes, the basic fea-

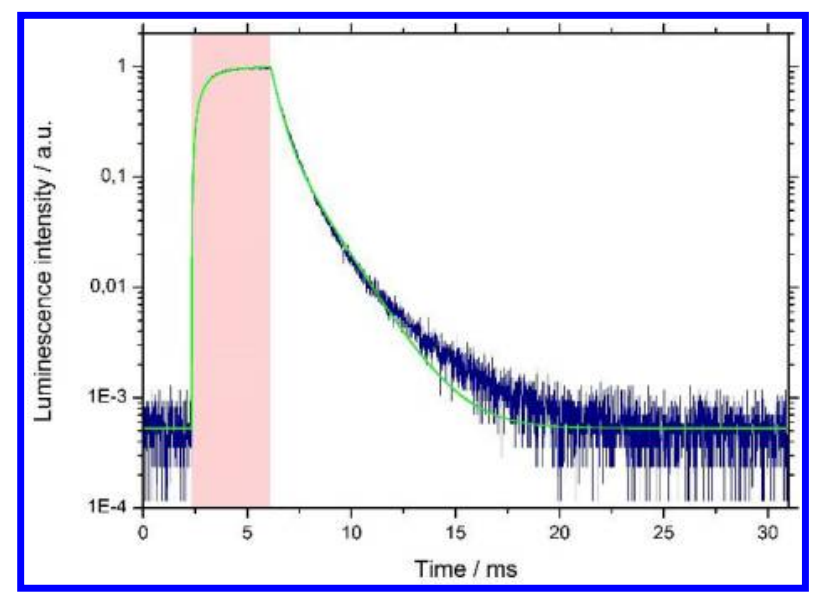

Figure 6. Evolution with time of the Tb centred UC emission intensity at $550 \mathrm{~nm}$ (in blue) upon time gated excitation at 975 $\mathrm{nm}$ (schematized in pink) for a $1.53 \mathrm{mM}$ solution of [YbL] in $\mathrm{D}_{2} \mathrm{O}(\mathrm{pD}=9.2)$ containing 0.5 equivalent of $\mathrm{TbCl}_{3} \cdot 6 \mathrm{H}_{2} \mathrm{O}$. The green curve represents the fit of the data according to a two Tb sites model (see text).

tures are the observation of an immediate decay of the UC efficiency after short-pulsed excitation, and the appearance in the UC spectrum of transitions which do not match the emission spectrum of the emitting atom, i.e. Tb, as a result of admixture with the Stark levels of $\mathrm{Yb}$ in the $\mathrm{Yb} / \mathrm{Tb}$ dimers. ${ }^{24}$

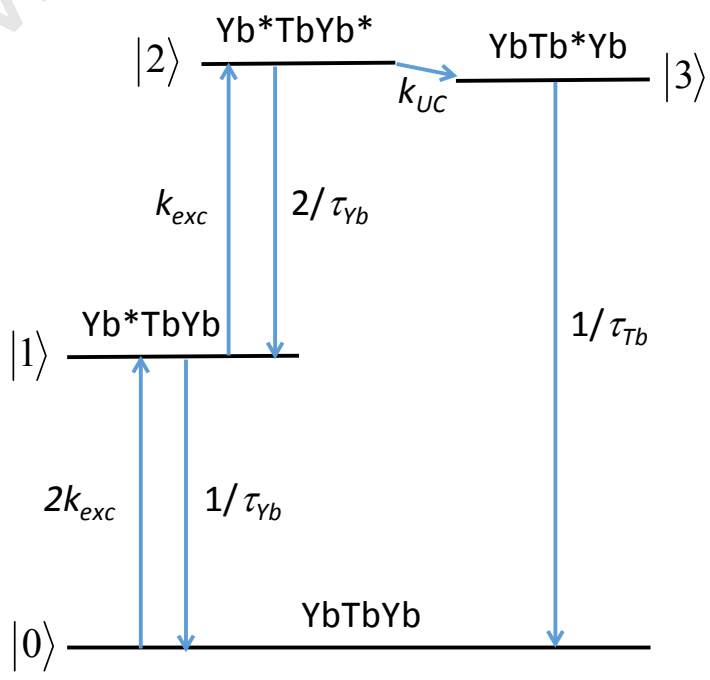

Figure 7. Energy level diagram of the cooperative UC photosensitization of $\mathrm{Tb}$ in the $\left[(\mathrm{YbL})_{2} \mathrm{~Tb}\right]$ supramolecular complex.

To get insights into the mechanism, we performed timeresolved luminescence measurements in which the continuous wave output of a $975 \mathrm{~nm}$ laser diode was electronically modulated to generate excitation pulses with a square temporal profile. Single photon events are detected at $550 \mathrm{~nm}$ using the time-correlated single photon 
counting approach. Full experimental details can be found in the experimental section, while the setup is schematized in the supplementary information section (Figure S6). A representative photon distribution over time is given in Figure 6.

As can be observed in Figure 6, the rise of the UC emission intensity is quite long, requiring few $\mathrm{ms}$ before it reaches steady-state. This slow rise is typical of a slow kinetic step related to the energy transfer during the cooperative energy transfer UC process. ${ }^{23}$ Considering the energy level diagram for the cooperative photosensitization UC process (Figure 7), and regarding a similar model proposed for ETU in supramolecular complexes, ${ }^{49}$ a mathematical model was developed to fit the measured evolution of the luminescence intensity with time. The evolution of the populations of the different states can be calculated using the following matrix description:

$$
\frac{d}{d t}\left(\begin{array}{c}
|0\rangle \\
|1\rangle \\
|2\rangle \\
|3\rangle
\end{array}\right)=\left(\begin{array}{cccc}
-2 k_{\text {exc }} & 1 / \tau_{Y b} & 0 & 1 / \tau_{T b} \\
2 k_{\text {exc }} & -1 / \tau_{Y b}-k_{e x c} & 2 / \tau_{Y b} & 0 \\
0 & k_{e x c} & -2 / \tau_{Y b}-k_{U C} & 0 \\
0 & 0 & k_{U C} & -1 / \tau_{T b}
\end{array}\right) \times\left(\begin{array}{c}
|0\rangle \\
|1\rangle \\
|2\rangle \\
|3\rangle
\end{array}\right)
$$

Where $k_{\text {exc }}$ is the pumping rate constant, $\tau_{Y b}$, is the excited state lifetime of $\mathrm{Yb}$ in the absence of $\mathrm{Tb}(10.2 \mu \mathrm{s}),{ }^{35} \tau_{T b}$, the excited state lifetime of $\mathrm{Tb}$ (fitted in the process) and $k_{U C}$, the rate of the energy transfer step (fitted). In this model, it is assumed that the absorption properties of the [YbL] unit are the same for all entities ([YbL] and $\left.\left[(\mathrm{YbL})_{2} \mathrm{~Tb}\right]\right)$. The pumping rate constant was determined using the relationship: $:^{21}$

$$
k_{e x c}=\frac{\lambda_{P}}{h c} P \sigma_{Y b}^{0 \rightarrow 1}
$$

with $\lambda_{P}$ is the pumping wavelength, $h$, the Planck's constant, $c$ the vacuum speed of light, $P$ the incident pump intensity and $\sigma_{Y b}^{0 \rightarrow 1}$ the absorption cross section (in $\mathrm{cm}^{2} / \mathrm{molec}$ ) of the $\mathrm{Yb}^{2} \mathrm{~F}_{7 / 2} \rightarrow{ }^{2} \mathrm{~F}_{5 / 2}$ transition obtained from the electronic absorption spectrum (Figure $\mathrm{S}_{2}$ ).

While fitting the data, it soon appeared that such a simplified model did not allow to properly describe the observed evolution of the emission intensity. In particular, the decay part shows a bi-exponential behaviour, pointing to the emission of two distinct $\mathrm{Tb}$ sites. This observation can be related to the presence of both the $\left[(\mathrm{YbL})_{2} \mathrm{~Tb}\right]$ and $\left[(\mathrm{YbL})_{2} \mathrm{~Tb}_{2}\right]$ species being present in solution even at only 0.5 equivalent of added $\mathrm{Tb}$. It was thus necessary to revise the model and to include the two heteropolynuclear species. This required the introduction of four new variable parameters in the fitting: the two luminescence lifetimes of the $\mathrm{Tb}$ atoms of the $\left[(\mathrm{YbL})_{2} \mathrm{~Tb}_{2}\right]$ complex, and the two UC rate constants associated to the populations of these two new $\mathrm{Tb}$ sites. A fitting with six variables being overdimensioned in respect to our data, we hypothesized that the introduction of the second $\mathrm{Tb}$ atom does only marginally change the structural properties of the $\left[(\mathrm{YbL})_{2} \mathrm{~Tb}\right]$ precursor. Consequently, the UC rate constant and luminescence lifetime of the $\mathrm{Tb}$ atom in $\left[(\mathrm{YbL})_{2} \mathrm{~Tb}\right]$ were assumed to be the same as that of one of the $\mathrm{Tb}$ atom of the $\left[(\mathrm{YbL})_{2} \mathrm{~Tb}_{2}\right]$ species, reducing the number of variable parameters to four: the two $\mathrm{Tb}$ luminescence lifetimes and the two UC rate constants. This model is illustrated by the energy level diagram represented in Figure $\mathrm{S}_{7}$ and its matrix description in Figure S8.

The data could well be fitted with this new model as can be seen in Figure 6 (green curve). From this fit, Tb luminescence lifetimes of $0.42 \pm 0.05 \mathrm{~ms}$ and $1.45 \pm 0.05 \mathrm{~ms}$ were determined with associated UC rate constants of 2330 \pm 30 and $278 \pm 4 \mathrm{~s}^{-1}$ respectively. The same analysis was performed on an equimolar solution of [YbL] and $\mathrm{Tb}$, and the corresponding figure with the fitted data is presented in Figure S13. The values obtained for the UC rate constants are in agreement with the $2000 \mathrm{~s}^{-1}$ value determined by Güdel and coworkers for single crystals of $\mathrm{SrCl}_{2}$ doped with $\mathrm{Yb}$ and $\mathrm{Tb}$ at $1 \% .^{23}$ However, great care should be taken with the comparison between our system in solution and the solid state data of Güdel et al. (room temperature and a laser peak power of $81 \mathrm{~W} . \mathrm{mm}^{-2}$ in our case and $100 \mathrm{~K}$ and $10^{7} \mathrm{~W} . \mathrm{mm}^{-2}$ for the work of Güdel). Additionally, one should keep in mind that our treatment, as that of Hauser and coworkers, 49 is related to intramolecular processes, in contrast to the intermolecular ones in the approach of Güdel. ${ }^{23}$ Interestingly, it is to be noticed that the faster energy transfer process is related to the shorter lived $\mathrm{Tb}$ excited state. Taking into account that this kind of cooperative sensitization is phonon assisted, one may expect the O-D oscillators of the solvent molecules to play a role in the phonon assistance, especially for the most solvated $\mathrm{Tb}$ cation, i.e. the one with the shorter excited state lifetime.

The efficiency of the UC process, $\eta_{U C}$, can be calculated using the relationship:

$$
\eta_{U C}=\frac{\sum k_{U C}}{\sum k_{U C}+k_{r}+k_{n r}}
$$

where $k_{U C}$ represents the UC energy transfer rate. The radiative rate constant $k_{r}$ of the $\mathrm{Yb}$ complexes is the inverse of $\tau_{r}$ (1.36 ms, vide supra), that is $735 \mathrm{~s}^{-1}$, while the non radiative rate constant $k_{n r}$ can be obtained by:

$\phi_{Y b}=\frac{k_{r}}{k_{r}+k_{n r}}$

$\phi_{\mathrm{Yb}}$ being the $\mathrm{Yb}$ centred luminescence quantum yield ( 0.75 $\%$, vide supra), giving a value of $97300 \mathrm{~s}^{-1}$ for $k_{n r}$. By this approach, the UC efficiency was calculated to be $2.6 \%$ in our conditions. Alternatively, $\eta_{U C}$ can be derived independently from the measurements of the $\mathrm{Yb}$ centred luminescence lifetimes in the absence $\left(\tau_{\mathrm{obs} Y b}=11.4 \mu \mathrm{s}\right.$ at $\mathrm{pD}$ $=7.2)$ and in the presence $\left(\tau_{Y b T b}=11.2 \mu \mathrm{s}\right.$ at $\left.\mathrm{pD} 7.1\right)$ of 0.5 equivalent of $\mathrm{Tb}$ using: 


$$
\eta_{U C}=1-\frac{\tau_{Y b T b}}{\tau_{Y b}}
$$

This approach yields a value of $2.4 \%$, in excellent agreement with that obtained from equation (5).

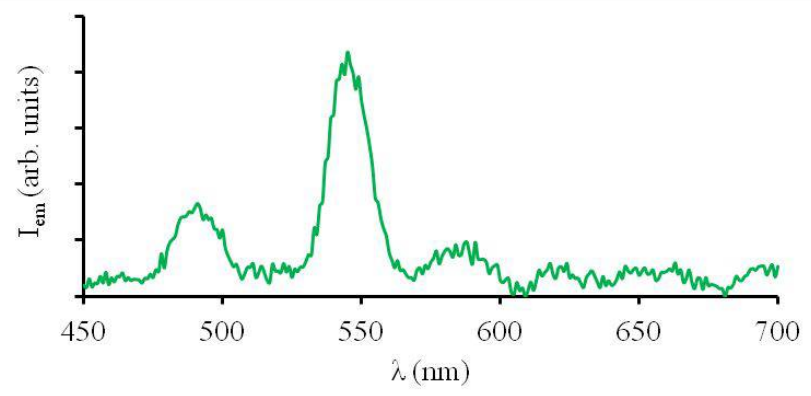

Figure 8. UC emission spectrum of an $11 \mathrm{mM}$ solution of $[\mathrm{YbL}]$ in the presence of one equivalent of $\mathrm{TbCl}_{3} \cdot 6 \mathrm{H}_{2} \mathrm{O}$ upon excitation at $980 \mathrm{~nm}\left(P_{980}=1.08 \mathrm{~W}\right)$.

UC in water. Considering the success obtained in observing $\mathrm{UC}$ in $\mathrm{D}_{2} \mathrm{O}$ with our system, we turned our attention towards the possibility of observing UC in nondeuterated water. Assuming that the rate of the UC energy transfer step is not perturbed by the change from $\mathrm{D}_{2} \mathrm{O}$ to $\mathrm{H}_{2} \mathrm{O}$ (which may not be fully true, when considering the likely assistance of phonons in the process), the efficiency of the phenomenon is thought to be related to the square of the probability of $\mathrm{Yb}$ to be in the excited state, itself related to the squared value of the ratio of the $\mathrm{Yb}$ excited state lifetimes in the two solvents. For a same set of concentrations and technical parameters (slits, excitation power,...) the UC emitted intensity in $\mathrm{H}_{2} \mathrm{O}$ should be related to that in $\mathrm{D}_{2} \mathrm{O}$ divided by $\left(\tau_{\mathrm{YbD}_{2} \mathrm{O}} / \tau_{\mathrm{YbH}_{2} \mathrm{O}}\right)^{2}=$ $(10.2 / 2.8)^{2}=13.0$. Additionally, the change from $\mathrm{D}_{2} \mathrm{O}$ to water will result in a decrease of the $\mathrm{Tb}$ emission intensity due to additional vibrational relaxation. Considering the long lifetime of $1.46 \mathrm{~ms}$ obtained by the fitting process and a hydration number of 2 to 5 water molecules, application of Beeby's equation ${ }^{14}$ showed that the decreased lifetime of $\mathrm{Tb}$ would result in a supplementary 1.5 to 3 -fold decrease in the UC intensity in water. Thus, a ca ten-fold increase of the concentration associated to a longer accumulation time should allow for observing UC in water. The experiment was run on an $11 \mathrm{mM}$ solution of [YbL] containing one equivalent of $\mathrm{TbCl}_{3} \cdot 6 \mathrm{H}_{2} \mathrm{O}$ and 120 scans were accumulated ( $\mathrm{six}$ times more than for $\mathrm{D}_{2} \mathrm{O}$ experiments, Figure 8).

As can be seen in Figure 8, the cooperative UC photosensitisation of $\mathrm{Tb}$ by $\mathrm{Yb}$ can also be observed in pure water, affording the first example of molecular UC in water at room temperature. Noteworthy, this result was obtained with a non-deuterated ligand, the synthesis of which being easily accessible. This observation paves the way to further improvements, potentially leading to a brand new family of luminescent tags based on molecular UC devices.

\section{EXPERIMENTAL SECTION}

Spectroscopy. Spectroscopic measurements were performed with $10 \times 10 \mathrm{~mm}^{2}$ quartz suprasil certified cells (Helma Analytics). UV/Vis absorption spectra were recorded on a Perkin-Elmer lambda 950 spectrometer. Steady-state emission spectra were recorded on an Edinburgh Instrument FLP920 spectrometer working with a continuous 45oW Xe Lamp and a red sensitive R928 photomultiplier from Hamamatsu in Peltier housing for visible detection (230 to $900 \mathrm{~nm}$ ) or a Hamamatsu R550972 photomultiplier for the Vis-NIR part. All spectra were corrected for the instrumental functions. For emission spectra upon UV excitation (Figure $\mathrm{S}_{4}$ and $\mathrm{S}_{5}$ ), a $399 \mathrm{~nm}$ cutoff filter was used to eliminate second-order artifacts. Phosphorescence lifetimes were measured on the same instrument working in the Multi Channel Spectroscopy (MCS) mode, using a Xenon flash lamp as the excitation source. For short $\mu$ s lifetimes, the intensity decay was corrected from the lamp intensity decay profile using a scattering solution of Ludox in water. Steady-state upconversion emission spectra were recorded on the FLP920 spectrometer using a 980 nm LED from Edinburgh Instrument with a $850 \mathrm{~nm}$ high pass filter between the source and the sample to remove any potential visible excitation. The power of the LED was calibrated using a FieldMate power meter from Coherent Technology. Unless otherwise stated, the spectra were recorded using the Peltier cooled R928 photomultiplier from Hamamatsu, using fully opened emission slit width $(20 \mathrm{~nm})$, by accumulation of 20 spectra at 1 point $/ \mathrm{nm}$, with a dwell time of $0.1 \mathrm{~s}$ per $\mathrm{nm}$.

Power dependent steady-state and time-resolved UC luminescence measurements were performed in quartz cuvettes (Hellma QS Semi-Micro Cells). The continuouswave laser beam $(\lambda=975 \mathrm{~nm})$ of a single mode fiber coupled laser diode was collimated (Thorlabs, TC12APC980 ) and focused in the cuvette by a $+100 \mathrm{~mm}$ focal length lens. From the measured beam waist radius $(\mathrm{w}=30.6 \mu \mathrm{m})$, we estimated the average excitation intensity in the beam waist to be $8.1 \mathrm{~kW} / \mathrm{cm}^{2}$ at maximum laser power. The emission of the sample was collected by a 10x / 0.25 numerical aperture objective and focused on an avalanche photodiode (Excelitas, SPCM-AQRH-16). The scattered laser light was removed by a low pass filter (Chroma,

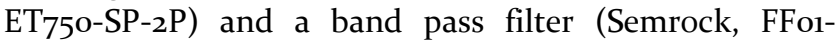
550/88-25). In the case of the steady-state measurements (emitted intensity as a function of excitation intensity) the output power of the laser was adjusted electronically (by varying the current intensity sent to the diode) and optically by using neutral density filters (Thorlabs) and systematically measured by a power meter (Newport, ${ }_{1917} \mathrm{R}$ and Ophir, 3oA-BB-18). The signal of the photodiode was collected by a computer equipped with a multifunction input/output card (National Instruments multifunction board, PCIe 6711). During time-resolved measurements, the laser output was modulated electronically at $32 \mathrm{~Hz}$ with a $12 \%$ duty cycle square waveform by a multifunction 
input/output card (National Instruments multifunction board, PCle 6361). The single photon events detected by the photodiode and the synchronization signal of the laser were recorded by a time-correlated single photon counting board (Becker-Hickl, SPC-830). The software SPCM 9.75 (Becker-Hickl) was used to both record the data and build the photon distribution over time. Experimental luminescence decays were fitted by using the coupled differential rate equations model discussed in main text in Matlab 2017b. A representation of the setup is schematized in Figure S6 (Supp. Inf.).

$\mathrm{X}$-ray crystal structure of the (YbL) complex. Data were collected on a D8 VENTURE Bruker AXS diffractometer operating with graphite-monochromated Mo-K $\alpha$ radiation $(\lambda=0.71073 \AA)$. Two twin components were found using the CELL_NOW program as implemented in the APEXIII program suite. The structures was solved by direct methods using the $S I R 92$ program $^{50}$ and then refined with full-matrix least-square methods based on $F^{2}$ (SHELXL$2014 / 7)^{51}$ with the aid of the WINGX program. ${ }^{52}$ All nonhydrogen atoms were refined with anisotropic atomic displacement parameters. The $\mathrm{H}$ atoms of phosphonate groups have been found in the electron density maps and refined as idealized hydroxyl group with torsion from electron density (AFIX 147 instruction), $\mathrm{H}$ atoms of water molecules were not clearly identified in the electron density maps and have been omitted in the refinement, other $\mathrm{H}$ atoms were finally included in their calculated positions. Crystallographic data on X-ray data collection and structure refinements are given in Table S2-S6. Crystallographic data for structural analysis of the $\mathrm{Yb}$ complex has been deposited with the Cambridge Crystallographic Data Centre under CCDC 1589358. Copies of this information is available free of charge from the Web site (www.ccdc.cam.ac.uk).

DFT calculations. Following our previous work,53 DFT calculations were performed with the hybrid meta-GGA TPSSh functional $5^{54}$ in conjunction with a large-core quasirelativistic effective core potential (ECP) and the related $(7 \mathrm{~s} 6 \mathrm{p} 5 \mathrm{~d}) /[5 \mathrm{~s} 4 \mathrm{P} 3 \mathrm{~d}]-\mathrm{GTO}$ basis set or $\mathrm{Yb}, 55$ and the standard $6-31 \mathrm{G}(\mathrm{d}, \mathrm{p})$ basis set for $\mathrm{C}, \mathrm{H}, \mathrm{N}, \mathrm{O}$ and P. Bulk water solvent effects were considered with the integral equation formalism of the polarized continuum model (IEFPCM)..$^{6}$

\section{CONCLUSION}

The strong kinetic and thermodynamic stability of the Ln complexes of ligand $\mathrm{L}$ associated to their large negative charges were advantageously used to form the heteropolynuclear $\left[(\mathrm{YbL})_{2} \mathrm{~Tb}\right]$ and $\left[(\mathrm{YbL})_{2} \mathrm{~Tb}_{2}\right]$ complexes in aqueous solutions. NIR excitation of the $\mathrm{Yb}$ atom in these heteronuclear edifices led to the observation of a cooperative photosensitization $\mathrm{UC}$ of $\mathrm{Tb}$ with emission in the visible domain. Time-resolved excitation experiments allowed to calculate the UC rate constants in the supramolecular adducts and to estimate a $2.6 \%$ efficiency of the UC step, that was confirmed by the decrease of $\mathrm{Yb}$ excited state lifetime in the presence of $\mathrm{Tb}$. The overall efficiency of the UC process was found to be rather low in $\mathrm{D}_{2} \mathrm{O}\left(1.4 \times 10^{-8}\right)$, but sufficient to envisage its observation in non-deuterated water. Hence, for the first time, this cooperative photosensitization UC could be observed at the molecular scale in an aqueous solution at room temperature. Careful analysis of the parameters that control the UC efficiency suggests that engineering of improved supramolecular edifices will allow additional optimizations, so that the development of UC molecular probes for applications in bio-analytical technologies may be envisaged.

\section{ASSOCIATED CONTENT}

Supporting Information. ${ }^{1} \mathrm{H}-\mathrm{NMR}$ spectrum of $[\mathrm{YbL}]$ in $\mathrm{D}_{2} \mathrm{O}$ in presence of $\mathrm{o}, 0.5$ and 1 equivalent of $\mathrm{LuCl}_{3}$ and $\mathrm{TbCl}_{3}{ }^{1} \mathrm{H}$-NMR spectrum of [LuL] in $\mathrm{D}_{2} \mathrm{O}$ in presence of o and 1 equivalent of $\mathrm{YbCl}_{3}$, Electronic absorption spectrum of $[\mathrm{YbL}]$ in $\mathrm{D}_{2} \mathrm{O}$ in the NIR region, Tb emitted intensity as a function of the $\mathrm{pD}$, Experimental setup used for the timeresolved UC emission intensity measurements (4 Figures), Full experimental Procedures for the calculation of the radiative lifetime of $\mathrm{Yb}$ and the UC quantum yield, Crystallographic data for the structure of the $\mathrm{Yb}$ complex (5 Tables) geometric factors for the calculations of ${ }^{1} \mathrm{H}-\mathrm{NMR}$ chemical shifts of the [YbL] complex (2 Tables), and Luminescence decay profiles of Eu recorded for two solutions of $[\mathrm{YbL}]$ in presence of 0.5 and 1 equivalent of $\mathrm{EuCl}_{3}$ in water can be find in the supporting information section. This material is available free of charge via the Internet at http://pubs.acs.org.

\section{AUTHOR INFORMATION}

\section{Corresponding Author}

*1.charbonn@unistra.fr

\section{ACKNOWLEDGMENT}

Doctor Robert Pansu (Ecole Normal Supérieure de Cachan, France) is gratefully acknowledged for his advices and fruitful discussions concerning the determination of the luminescence UC QY. C. P.-I. thanks Centro de Supercomputación de Galicia for providing the computer facilities.

\section{REFERENCES}

(1) Auzel, F. Upconversion and anti-Stokes processes with $\mathrm{f}$ and d Ions in solids. Chem. Rev. 2004, 104, 139.

(2) Gamelin, D.R.; Güdel, H.U. Design of luminescent inorganic materials: new photophysical processes studied by optical spectroscopy. Acc. Chem. Res. 2ooo, 33, 235.

(3) Chen, G.; Qiu, H.; Prasad, P.N.; Chen, X. Upconversion nanoparticles: design, nanochemistry, and applications in theranostics. Chem. Rev. 2014, 114, 5161.

(4) Haase, M.; Schäfer, H. Upconverting nanoparticles. Angew. Chem. Int. Ed. 2011, 50, 5808.

(5) Zheng, W.; Huang, P.; Tu, D.; Ma, E.; Zhu, H.; Chen, X. Lanthanide-doped upconversion nano-bioprobes: electronic 
structures, optical properties, and biodetection. Chem. Soc. Rev. 2015, 44, 1379.

(6) Suffren, Y.; Golesorkhi, B.; Zare, D.; Guénée, L.; Nozary, H.; Eliseeva, S. V.; Petoud, S.; Hauser, A.; Piguet, C. Taming Lanthanide-Centered Upconversion at the Molecular Level. Inorg. Chem. 2016, 55, 9964.

(7) Aboshyan-Sorgho, L.; Besnard, C.; Pattison, P.; Kittilstved, K.R.; Aebischer, A.; Bünzli, J.-C.G.; Hauser, A.; Piguet, C. Near infrared to visible light upconversion in a molecular trinuclear df-d complex. Angew. Chem. Int. Ed. 2011, 50, 4108.

(8) Hyppänen, I.; Lahtinen, S.; Ääritalo, T.; Mäkelä, J.; Kankare, J.; Soukka, T. Photon upconversion in a molecular lanthanide complex in anhydrous solution at room temperature. ACS Photonics 2014, 1, 394.

(9) Nonat, A.; Chan, C.F.; Liu, T.; Platas-Iglesias, C.; Wong, K.L.; Charbonnière, L.J. Room temperature molecular up conversion in solution. Nature Commun. 2016, 7, 11978.

(10) Souri, N.; Tian, P.; Platas-Iglesias, C.; Chafaa, S.; Wong, K.L.; Nonat, A.; Charbonnière, L.J. Upconverted photosensitization of Tb visible emission by NIR Yb excitation in descrete supramolecular heteropolynuclear complexes. J. Am. Chem. Soc. 2017, 139, 1456.

(11) Gnach, A.; Lipinski, T.; Bednarkiewicz, A.; Rybka, J.; Capobianco, J.A. Upconverting nanoparticles: assessing the toxicity. Chem. Soc. Rev. 2015, 44, 1561.

(12) Maeda, H. Tumor-selective delivery of macromolecular drugs via the EPR effect: Background and future prospects. Bioconjugate Chem. 2010, 21, 797.

(13) Charbonnière, L.J. Bringing upconversion down to the molecular scale. Dalton Trans. 2018, 47, 8566.

(14) Beeby, A.; Clarkson, I. M.; Dickins, R. S.; Faulkner, S.; Parker, D.; Royle, L.; de Sousa, A. S.; Williams, J. A. G.; Woods, M. Non-radiative deactivation of the excited states of europium, terbium and ytterbium complexes by proximate energy-matched $\mathrm{OH}, \mathrm{NH}$ and $\mathrm{CH}$ oscillators: an improved luminescence method for establishing solution hydration states. J. Chem. Soc. Perkin Trans 2, 1999, 493.

(15) Horrocks, W. D. W. Jr; Sudnick, D. Lanthanide ion probes of structure in biology. Laser-induced luminescence decay constants provide a direct measure of the number of metalcoordinated water molecules. J. Am. Chem. Soc., 1979, 101, 334.

(16) Bischof, C.; Wahsner, J.; Scholten, J.; Trosien, S.; Seitz, M. Quantification of $\mathrm{C}-\mathrm{H}$ quenching in near-IR luminescent ytterbium and neodymium cryptates. J. Am. Chem. Soc. 2010, 132, 14334

(17) Ning, Y.; Tang, J.; Liu, Y.-W.; Jing, J.; Sun, Y.; Zhang, J.-L. Highly luminescent, biocompatible ytterbium(III)

complexes as near-infrared fluorophores for living cell imaging. Chem. Sci. 2018, 9, 3742.

(18) Hu, J.-Y.; Ning, Y.; Meng, Y.-S.; Zhang, J.; Wu, Z.-Y.; Gao, S.; Zhang, J.-L. Highly near-IR emissive ytterbium(iii) complexes with unprecedented quantum yields. Chem. Sci. 2017, 8, 2702.

(19) Doffek, C.; Seitz, M. The radiative lifetime in near-IR luminescent ytterbium cryptates: the key to extremely high quantum yields. Angew. Chem. Int. Ed. 2015, 54, 9719.

(20) Zhang, T.; Zhu, X.; Cheng, C.C.W.; Kwok, W.-M.; Tam, H.L.; Hao, J.; Kwong, D.W.J.; Wong, W.-K.; Wong, K.-L. Watersoluble mitochondria-specific ytterbium complex with impressive NIR emission. J. Am. Chem. Soc. 2011, 133, 20120.

(21) Auzel, F.; Goldner, P. Towards rare-earth clustering control in doped glasses. Opt. Mater. 2001, 16, 93.

(22) Zare, D.; Suffren, Y.; Guénée, L.; Eliseeva, S.V.; Nozary, H.; Aboshyan-Sorgho, L.; Petoud, S.; Hauser, A.; Piguet, C. Smaller than a nanoparticle with the design of discrete polynuclear molecular complexes displaying near-infrared to visible upconversion. Dalton Trans. 2015, 44, 2529.

(23) Salley, G.M.; Valiente, R.; Güdel, H.U. Phonon-assisted cooperative sensitization of $\mathrm{Tb}^{3+}$ in $\mathrm{SrCl}_{2}: \mathrm{Yb}, \mathrm{Tb}$. J. Phys.: Condens. Matter 2002, 14, 5461.

(24) Salley, G.M.; Valiente, R.; Güdel, H.U. Cooperative $\mathrm{Yb}^{3+}-\mathrm{Tb}^{3+}$ dimer excitations and upconversion in $\mathrm{Cs}_{3} \mathrm{~Tb}_{2} \mathrm{Br}_{9}: \mathrm{Yb}^{3+}$. Phys. Rev. B, 2003, 67, 134111.

(25) Salley, G.M.; Valiente, R.; Güdel, H.U. Luminescence upconversion mechanisms in $\mathrm{Yb}^{3+}-\mathrm{Tb}^{3+}$ systems. J. Lumin. 2001, 94-95, 305.

(26) Abada, S.; Lecointre, A.; Elhabiri, M.; Charbonnière, L.J. Formation of very stable and selective $\mathrm{Cu}$ (II) complexes with a non-macrocyclic ligand: can basicity rival pre-organization? Dalton Trans. 2010, 39, 9055.

(27) Lukes, I.; Kotek, J.; Vojtisek, P.; Hermann, P. Complexes of tetraazacycles bearing methylphosphinic/phosphonic acid pendant arms with copper(II), zinc(II) and lanthanides(III). A comparison with their acetic acid analogues. Coord. Chem. Rev. 2001, 216-217, 287.

(28) Benetollo, F.; Bombieri, G.; Calabi, L.; Aime, S.; Botta, M. Structural variations across the lanthanide series of macrocyclic DOTA complexes: insights into the design of contrast agents for magnetic resonance imaging. Inorg. Chem. 2003, 42, 148.

(29) Avecilla, F.; Peters, J.A.; Geraldes, C.F.G.C. X-ray crystal structure of a sodium salt of $[\mathrm{Gd}(\mathrm{DOTP})]^{5^{-}}$: implications for its second-sphere relaxivity and the ${ }^{23} \mathrm{Na}$ NMR hyperfine shift effects of [Tm(DOTP) $]^{5-}$. Eur. J. Inorg. Chem. 2003, 4179.

(30) Pellegatti, L.; Zhang, J.; Drahos, B.; Villette, S.; Suzenet, F.; Guillaumet, G.; Petoud, S.; Tóth, E. Pyridine-based lanthanide complexes: towards bimodal agents operating as near infrared luminescent and MRI reporters. Chem. Commun. 20o8, 6591.

(31) Abada, S.; Lecointre, A.; Elhabiri, M.; Esteban-Gomez, D.; Platas-Iglesias, C.; Tallec, G.; Mazzanti, M.; Charbonnière, L.J. Highly relaxing gadolinium based MRI contrast agents responsive to $\mathrm{Mg}^{2+}$ sensing. Chem. Commun. 2012, 48, 4085.

(32) Aime, S.; Gianolo, S.; Corpillo, D.; Cavalotti, C.; Palmisano, G.; Sisti, M.; Giovenzana, G.B.; Pagliarin, R. Designing novel contrast agents for magnetic resonance imaging. Synthesis and relaxometric characterization of three gadolinium(III) complexes based on functionalized pyridine-containing macrocyclic ligands. Helv. Chim. Acta, 2033, 86, 615.

(33) Elhabiri, M.; Abada, S.; Sy, M.; Nonat, A.; Choquet, P.; Esteban-Gomez, D.; Cassino, C.; Platas-Iglesias, C.; Botta, M.; Charbonnière, L.J. Importance of outer-sphere and aggregation phenomena in the relaxation properties of phosphonated gadolinium complexes with potential applications as MRI contrast agents. Chem. Eur. J. 2015, 21, 6535.

(34) Souri, N.; Tian, P.; Lecointre, A.; lemaire, Z.; Chafaa, S.; Strub, J.-M.; Cianférani, S.; Elhabiri, M.; Platas-Iglesias, C.; Charbonnière, L.J. Step by step assembly of polynuclear lanthanide complexes with a phosphonated bipyridine ligand. Inorg. Chem. 2016, 55, 12962.

(35) Salaam, J.; Tabti, L.; Bahamyirou, S.; Lecointre, A.; Hernandez Alba, O.; Jeannin, O.; Camerel, F.; Cianférani, S.; Bentouhami, E.; Nonat, A.M.; Charbonnière, L.J. Formation of mono- and polynuclear luminescent lanthanide complexes based on the coordination of preorganized phosphonated pyridines. Inorg. Chem. 2018, 57, 6095 .

(36) Llunell, M.; Casanova, D.; Cirera, J.; Alemany, P.; Alvarez, S. SHAPE (version 2.1), Barcelona, 2013.

(37) Ruiz-Martinez, A.; Casanova, D.; Alvarez, S. Polyhedral Structures with an Odd Number of Vertices: Nine-Coordinate Metal Compounds. Chem. Eur. J., 2008, 14, 1291. 
(38) Peters, J. A.; Huskens, J. \& Raber, D. J. Lanthanide induced shifts and relaxation rate enhancements. Prog. Nucl. Magn. Reson. Spectrosc. 28, 283-350 (1996).

(39) Aime, S.; Barbero, L.; Botta, M.; Ermondi, G. Determination of metal-proton distances and electronic relaxation times in lanthanide complexes by nuclear magnetic resonance spectroscopy. J. Chem. Soc., Dalton Trans. 1992, 225.

(40) Frisch, M. J.; Trucks, G. W.; Schlegel, H. B.; Scuseria, G. E.; Robb, M. A.; Cheeseman, J. R.; Scalmani, G.; Barone, V.; Mennucci, B.; Petersson, G. A., Nakatsuji,H.; Caricato, M.; Li, X.; Hratchian, H. P.; Izmaylov, A. F.; Bloino, J.; Zheng, G.; Sonnenberg, J. L.; Hada, M.; Ehara, M.; Toyota, K.; Fukuda, R.; Hasegawa, J.; Ishida, M.; Nakajima, T.; Honda, Y.; Kitao, O.; Nakai, H.; Vreven, T.; Montgomery Jr., J.A.; Peralta, J. E.; Ogliaro, F.; Bearpark, M.; Heyd, J. J.; Brothers, E.; Kudin, K. N.; Staroverov, V. N.; Kobayashi, R.; Normand, J.; Raghavachari, K.; Rendell, A.; Burant, J. C. ; Iyengar, S. S.; Tomasi, J.; Cossi, M.; Rega, N.; Millam, J.M.; Klene, M. ; Knox, J. E.; Cross, J. B.; Bakken, V.; Adamo, C.; Jaramillo, J.; Gomperts, R. ; Stratmann, R. E.; Yazyev, O.; Austin, A. J.; Cammi, R.; Pomelli, C.; Ochterski, J. W.; Martin, R. L.; Morokuma, K.; Zakrzewski, V. G.; Voth, G.A.; Salvador, P.; Dannenberg, J. J.; Dapprich, S.; Daniels, A. D.; Farkas, Ö.; Foresman, J. B.; Ortiz, J. V.; Cioslowski, J.; Fox, D.J. Gaussian o9, Revision E.o1, Gaussian, Inc.: Wallingford CT, 2009.

(41) Forsberg, J. H.; Delaney, R. M.; Zhao, Q.; Harakas, G.; Chandran, R. Analyzing lanthanide-induced shifts in the NMR spectra of lanthanide(III) complexes derived from 1,4,7,10tetrakis(N,N-diethylacetamido)-1,4,7,10-tetraazacyclododecane. Inorg. Chem. 1995, 34, 3705.

(42) Blackburn, O. A.; Routledge, J. D.; Jennings, L. B.; Rees, N. H.; Kenwright, A. M.; Beer, P. D.; Faulkner, S. Substituent effects on fluoride binding by lanthanide complexes of DOTAtetraamides. Dalton Trans. 2016, 45, 3070.

(43) Ouali, N.; Bocquet, B.; Rigault, S.; Morgantini, P.-Y.; Weber, J.; Piguet, C. Analysis of paramagnetic NMR spectra of triple-helical lanthanide complexes with 2,6-dipicolinic acid revisited: a new assignment of structural changes and crystal-field effects 25 years later. Inorg. Chem. 2002, 41, 1436.

(44) Blackburn, O. A.; Chilton. N. F.; Keller, K.; Tait, C. E.; Myers, W. K.; McInnes, E. J. L.; Kenwright, A. M.; Beer, P. D.; Timmel, C. R.; Faulkner, S. Spectroscopic and crystal field consequences of fluoride binding by $[\mathrm{Yb} \cdot \mathrm{DTMA}]^{3+}$ in aqueous solution. Angew. Chem. Int. Ed. 2015, 54, 10783.

(45) Werts, M.H.V.; Jukes, R.T.F.; Verhoeven, J.W. The emission spectrum and the radiative lifetime of $\mathrm{Eu}^{3+}$ in luminescent lanthanide complexes. Phys. Chem. Chem. Phys. 2002, 4, 1542.

(46) Eliseeva, S.; Bünzli, J.-C.G. Lanthanide luminescence for functional materials and bio-sciences. Chem. Soc. Rev. 2010, 39, 189.

(47) Pollnau, M.; Gamelin, D.R.; Lüthi, S.R.; Güdel, H.U. Power dependence of upconversion luminescence in lanthanide and transition-metal-ion systems. Phys. Rev. B: Condens. Matter, 2000, 61, 3337.

(48) Weibel, N.; Charbonnière, L.J.; Guardigli, M.; Roda, A.; Ziessel, R. Engineering of highly luminescent lanthanide tags suitable for protein labeling and time-resolved luminescence imaging. J. Am. Chem. Soc. 2004, 126, 4888.

(49) Suffren, Y.; Zare, D.; Eliseeva, S. V.; Guénée, L.; Nozary, H.; Lathion, T.; Aboshyan-Sorgho, L.; Petoud, S.; Hauser, A.; Piguet, C. Near-infrared to visible light-upconversion in molecules: from dream to reality. J. Phys. Chem. C 2013, 117, 26957.

(50) Altomare, A.; Burla, M. C.; Camalli, M.; Cascarano, G. L.; Giacovazzo, C.; Guagliardi, A.; Moliterni, A. G. G.; Polidori, G.;
Spagna, R. SIR92 - a program for automatic solution of crystal structures by direct methods. J. Appl. Crystallogr. 1999, 32, 115.

(51) Sheldrick G. M. Crystal structure refinement with SHELXL. Acta Cryst. C 2015, 71, 3.

(52) Farrugia L. WinGX and ORTEP for Windows: an update. J. Appl. Cryst. 2012, 45, 849 .

(53) Regueiro-Figueroa, M.; Platas-Iglesias, C. Toward the prediction of water exchange rates in magnetic resonance imaging contrast agents: a density functional theory study. J. Phys. Chem. A 2015, 119, 6436.

(54) Tao, J. M.; Perdew, J. P.; Staroverov, V. N.; Scuseria, G. E. Climbing the density functional ladder: non-empirical metageneralized gradient approximation designed for molecules and solids. Phys. Rev. Lett. 2003, 91, 146401.

(55) Dolg, M.; Stoll, H.; Savin, A.; Preuss, H. Energy-adjusted pseudopotentials for the rare earth elements. Theor. Chim. Acta 1989, 75, 173 .

(56) Tomasi, J.; Mennucci, B.; Cammi, R. Quantum mechanical continuum solvation models. Chem. Rev. 2005, 105, 2999.

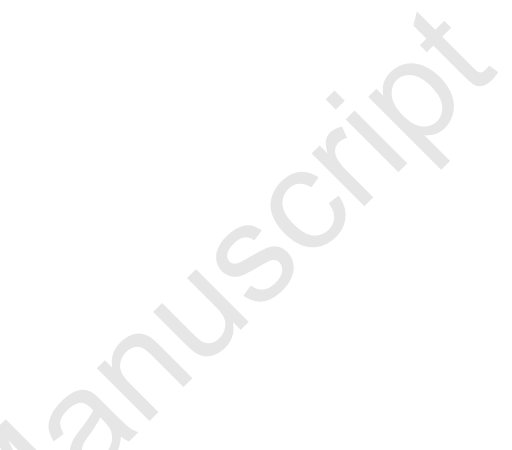




\section{Table Of Content}

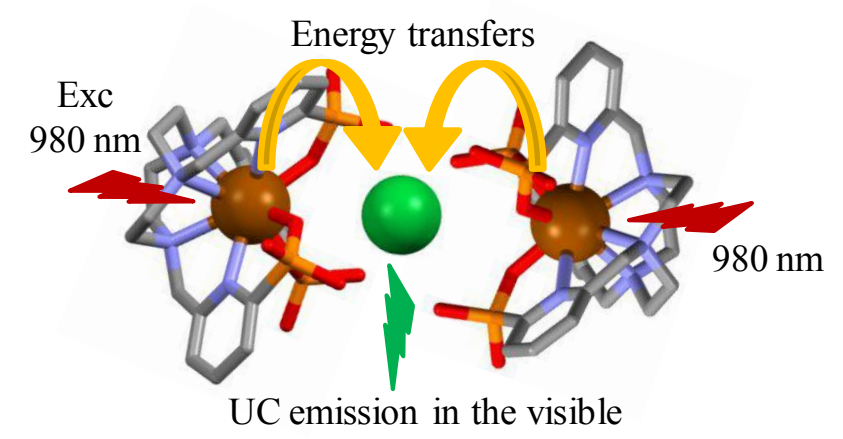

